\title{
Design and Implementation an e-Hospital System at Kurdistan
}

\author{
Mohamed Jasim Ahmed \\ Department of Information Systems Engineering. \\ Erbil Technical Engineering College \\ Erbil polytechnic university \\ Erbil, Iraq \\ mja.ise@yahoo.com
}

\author{
Subhi R. M. Zeebaree \\ Department of Computers and Communications Engineering \\ Engineering College \\ Nawroz University \\ Duhok, Iraq \\ subhizebari.akre@gmail.com
}

\begin{abstract}
The utilization of Information and Communication Technologies (ICT) have developed quickly. Traditional Healthcare (TH) which designates paper-predicated system is expeditious giving way to $e$ health system in most developed countries. Virtually all hospitals in the Kurdistan Region (KR) are utilizing TH. This paper deals with designing and implementing a web based electronic hospital system (WBEHS) in Shorsh General Hospital (SGH) in Slemani city. The system solves traditional style quandaries by transmuting the traditional paper-based healthcare system into a fully electronic system containing multi modules such as (Physician, X-Ray, Pharmacy, Laboratories, Ultrasound). The staff of SGH participated in the implementation and obtaining the results which have been evaluated by utilizing System Usability Scale (SUS). The overall evaluation score of the questionnaire was (79. 459\%) which can be considered as a good result.
\end{abstract}

Keywords: e-health. e-hospital. e-government. Electronic medical records. Web based application. Kurdistan.

\section{INTRODUCTION}

Due to Millennium Development Goals (MDGs) set by world leaders more than decade ago have made an astronomically immense influence on billions of people's live. By preparing for sustainable development, no doubt that more administrations are faced with a set of complex challenges. Ecumenical challenges including poverty, inequality, peace and security, are such that no single ministry can efficaciously deal with them on their own. Efficacious collaboration among agencies across all levels of government is essential, as it is with nongovernmental actors, to ascertain good governance and good development outcomes. Collaborative governance is crucial to amend people's lives. Essential accommodations that meet citizen needs, provide opportunities for economic growth, as well as facilitate citizen engagement. The key of transforming public administration into an instrument of sustainable development is e-government and innovation. Through innovation and e-government, public administrations around the world can be more efficient, offer healthier services and respond to demands for transparency and accountability [1].

This paper is concerned with implementation of e-health system in SGH. E-health is one of the most important sectors of E-government scope. The notion of e-health is very comprehensive, ranging from IT and new technologies to health [2]. It characterizes not only an advanced technical tool, but also an attitude, a way of thinking and global thinking, to improve health care locally, regionally, and worldwide by using information and communication technology. Moreover, it is a developing field in the intersection of medical informatics, public health and business, referring to health services and information delivered or enhanced through the Internet and related technologies [3].

The "e" in e-health does not only stand for "electronic," but implies a number of other "e's," which together perhaps best characterize what e-health is all about (or what it should be) which are: Efficiency, Enhancing quality of care, Evidence based, Empowerment of consumers and patients, Enabling information exchange, Extending the scope of health care, and Ethics, Equity [4].

The main factors in E-health Comparing to the traditional health sectors, e-health require harmonization with new players whose cultures, objectives and traditions are different such as: United Nations agencies, Government authorities, Academic and research institutions, Health professionals, Consumers, patients and their associations, Non-governmental organizations, the private sector, including foundations and industries related to health and ICTs [5].

The problem statement of this paper is to change the traditional paper based healthcare system in KR into a fully electronic system. Hence, reducing the gap between health sector in KR and developed countries that use ehealth system. A successful implementation of a new system is more than just the technical installation; the system also needs to support work routines and practices well enough to succeed and replace old procedures. This requires flexibility from both the system and its users, where both parties need to familiarize mutually to each other. The proposed system in this paper has been designed depending on academic methodology to be depended for all KR hospitals in future. Hence this system will contribute to support strongly the health sector at Kurdistan.

\section{LITERATURE REVIEW}

B. O. Oguntunde et al, developed a framework for a multi-tier Internet Service architecture for doctors' directory, that offers a relaxed and suitable technique for patients to access data and get appointment with doctors in various regions. The system additionally provided data about hospitals, doctors, their locations and 
availability. The system consisted of three modules (Doctors, Registration and login). They designed the system utilizing a 3-tier Internet service architecture consisted of a client tier (web browser), an application tier built on Apache and PHP, and a database tier on MySQL [6].

Gheyath $\mathrm{M}$ et al. proposed a Tiered Architecture Performance Analysis of Web-based Healthcare Systems in which the prototypes were integrated in one homepage and connected by the hyperlink recommendation method. The tiered architectures namely single, two, and three have a consequential role in Web-Based Healthcare (WBH) system, and each of them can be used for different purposes in the Hospital/Clinic [7].

Conceicao Granja et al. proposed a development of a hospital-patient web-based communication tool for north Norwegian university hospital in which enable the hospital to pre-operative planning. They planned to reduce the number of elective surgery cancellations that caused by the lack of information that existed but was not available when required for surgery planning [8].

Rasha T. Hameed et al, addressed a design of eHealthcare management system in Iraq. They recommended a model of designing flexible e-healthcare management system based on Cloud Computing and Service Oriented Architecture (SOA). They discussed the major problems and disadvantages of paper based system in Iraq hospitals, and produced their system as the relevant solution for the problems [9].

The shortcoming of systems with references [6], [7], [8], and [9] comparing with the proposed WBEHS is that the mentioned systems suffers from the lack of new and latest tools that makes the application flexible and easy to use. Also, it did not implement really it just a theoretical suggested system, and the test and evaluation was not real test it organized using simulation tools. While the proposed the flexible and user friendly WBEHS designed with most recent tools, implemented and evaluated actually in SGH at Sulaimani city KR.

\section{METHODS AND MATERIALS}

The WBEHS is designed in accordance with the requirements of SGH structure. A database and various web application implements utilized for the implementation of the proposed system. Web server offers interface to users who access the system over the web, and the database is used as storage of information entered by the users. The application cannot achieve its purposes without the database. However, the database alone is not adequate. Various tools of programming languages, web services, and databases are applied to the system, such as: HTML5, CSS, JavaScript, jQuery, Bootstrap, PHP, Laravel, MySQL, DataTables, AJAX and Google reCAPTCHA.

\subsection{The Architecture of the WBEHS}

The main three layers of the WBEHS shown in Fig. 1:

- Presentation layer (View Layer): The technologies usually involved in this layer on the web development context are mainly: HTML5, CSS, JavaScript (includes: Ajax and jQuery), and Bootstrap.

- Business Logic Layer: This layer of deals with the logic of the program, characterized by the server-side written in PHP language and communicates with presentation layer via HTML forms and JavaScript queries.

- Data layer: This layer is responsible of saving all coming data to MySQL database via logic layer.

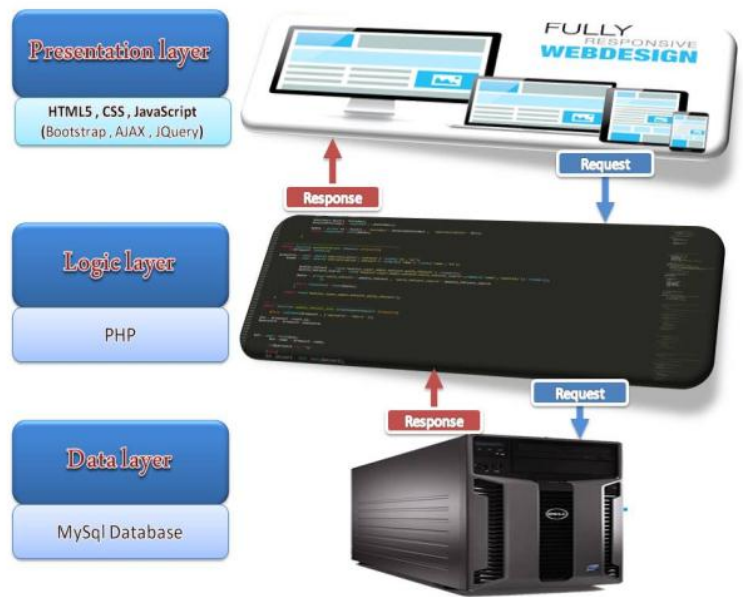

Figure 1 Main architecture of the WBEHS

\subsection{The Mechanism of WBEHS Design}

The mechanism of the proposed system involves: Webpage Effects such as (hover, color, focus, resize, animation), Processing which includes (PHP, JavaScript and AJAX Requirements), Saving and Retrieving data (PHP and SQL), System Functional Requirements which includes (System's Administrator, Staff, and Patients), Nonfunctional Requirements which includes (Usability, Security, Reliability, Accessibility, and Extensibility), Software requirements (Microsoft Windows 10 operating system, MySQL Database (phpMyadmin), Laravel Framework, Xampp server, DataTables, Bootstrap, Web browser and Internet service.

The Hardware Requirements which includes (Serverside: CPU: Core(TM) i5-4200U 2.30 GHZ, Architecture: 64 bits, RAM: 4GB, HDD: 500GB, and Client-side: can be the same as the server side or lower performance. The minimum requirement of the External Clients devices is the ability of browsing the web, and Internal Network.

The internal client-side: are the users of modules (Physician, Pharmacy, Lab, X-Ray, Reception, etc.) there will be (within SGH) connected with internal network through a switch. While the External Clients are connected to the system through internet service. 


\subsection{The Proposed System Services and Algorithms}

The proposed WBEHS involves a number of services provided by related modules as shown in Fig. 2.

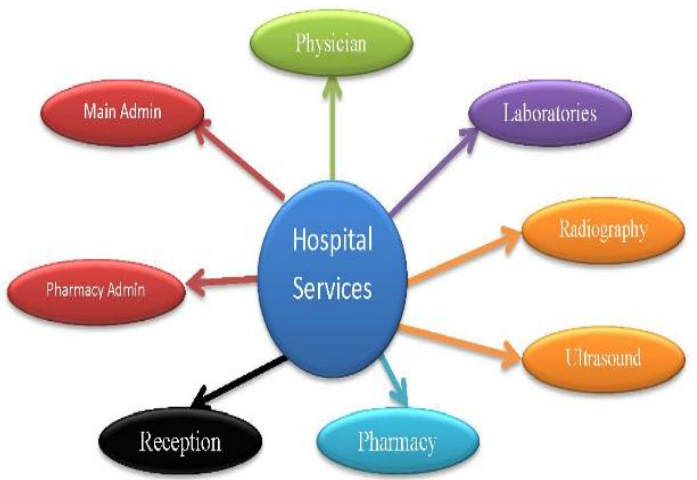

Figure 2 The proposed system services

The depended modules in the proposed system are: Super Admin Module, Pharmacy Admin Module, Reception Module, Physician Module, X-Ray Module, Ultrasound Module, and Laboratories Module as shown in Fig. 3.

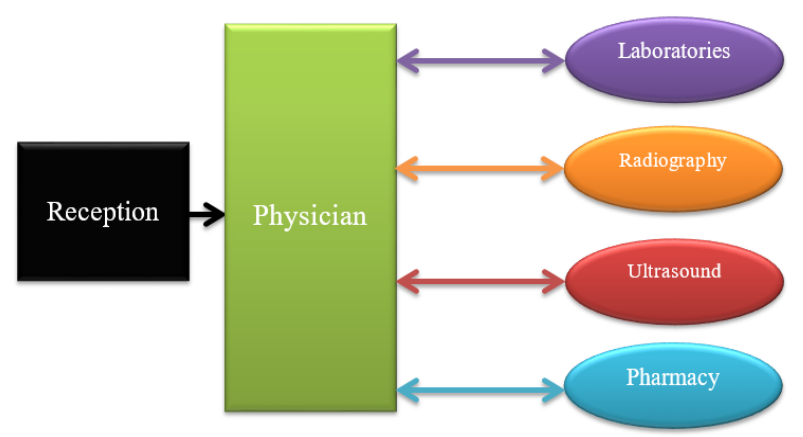

Figure 3 Modules dataflow

\section{RESULTS}

The implementation and evaluation of the proposed system have been applied in SGH in Sulaymaniyah city. The web-based application consists of several modules and pages, because of the multiplicity of main-pages, subpages and other details, consequently samples of the modules will be elucidated.

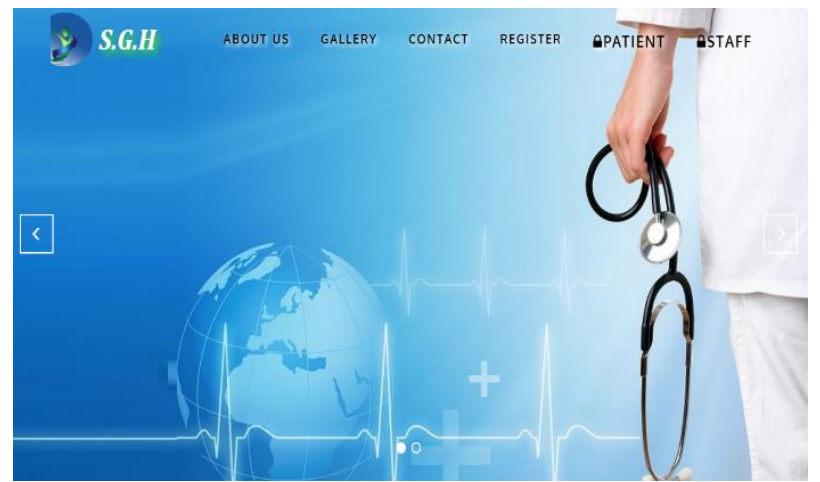

Figure 4 The Homepage of the proposed system
The homepage can be accessed by both registered and unregistered persons. The patient or any person who visits the site can contact and send his/her notice the hospital through Contact Section. Google reCAPTCHA is used as a protection for the contact form. as shown in Fig. 5.

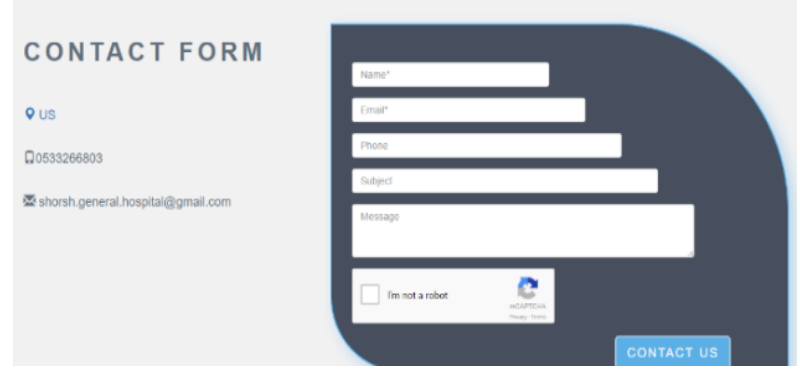

Figure 5 Contact page

If the patient had been registered so he can directly login to his account by email a password, otherwise he must register through the Registration Section as shown in Fig. 6.

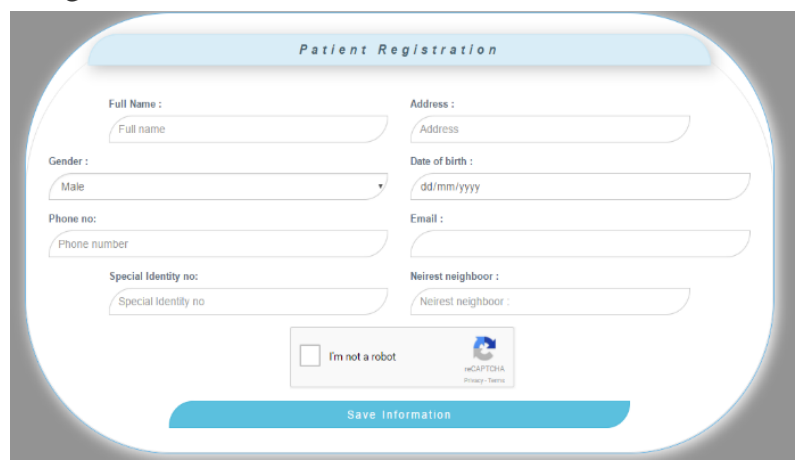

Figure 6 Patient Registration page

Through login form shown in Fig. 7, each user can access his/her account. After successful login, the user will redirect be the to his module automatically according to his specialization.

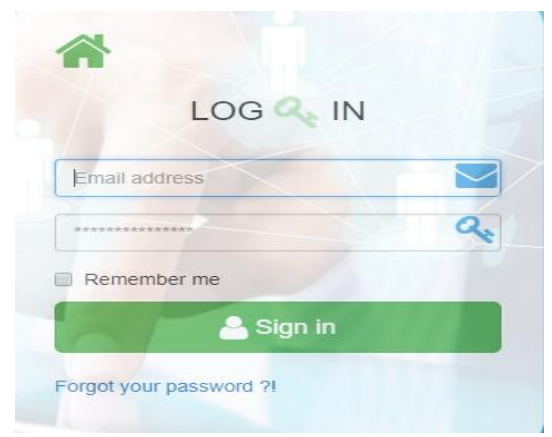

Figure 7 Login form

The login form contains a (Forgot your password ?!) link which redirect the user to the (Change password form) as shown in Fig. 8. The user must have a real email that exists in the database to be able to receive a temporary link to the (Reset password Form). As a security step, this link will be available for a certain period (one hour depended as a default setting), and this period can be changed by the Admin. 


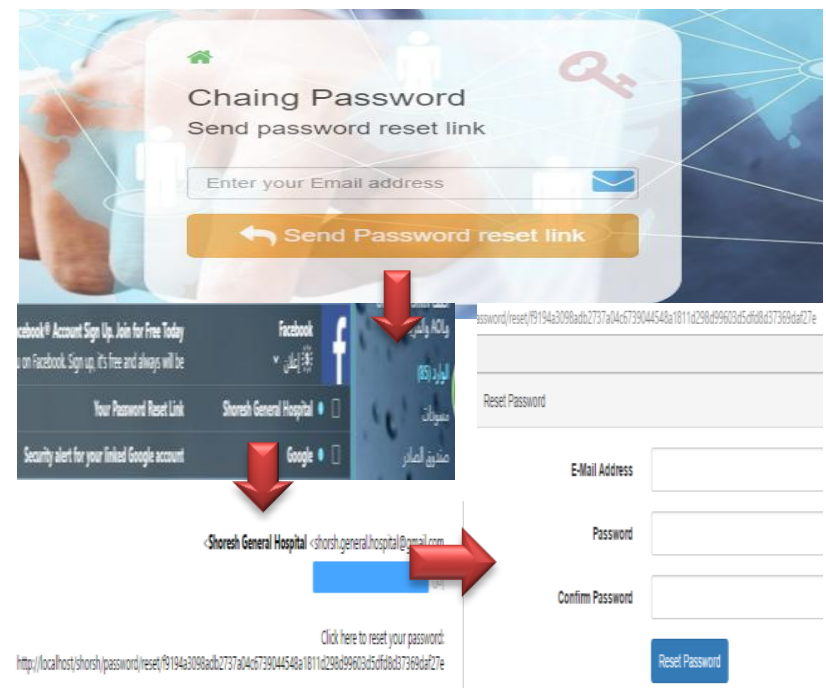

Figure 8 Change password forms and links

The system supports multiple modules (Reception, Patient, Physician, Lab, X-Ray, Ultrasound, Pharmacy and Admin) modules. Each module is authorized and can be accessed only by users who have the authorization. The modules provide facilities and services to the patient needs according to the physician instructions. The main activities of patient module are; Get Appointment, Cancel Appointment, Previous Diagnosis, Edit Profile and Logout as shown in Fig. 9.

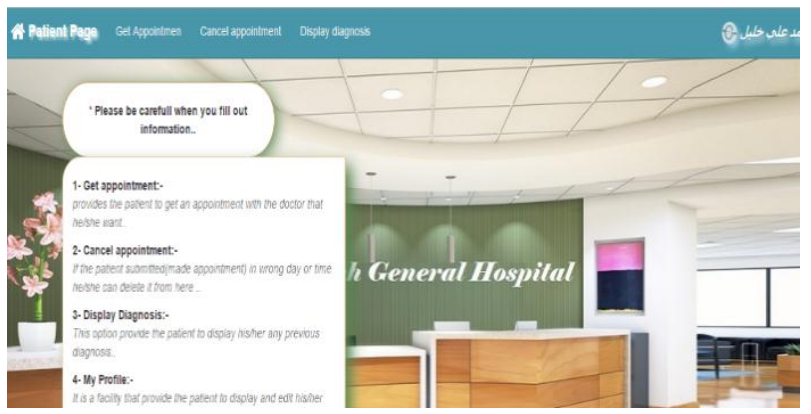

Figure 9 Patient module main page

The physician main page holds a number of hyperlinks; each link helps the physicians to transfer to other web pages to perform a particular task(s); which are (Daily Appointments, Appointments in period, Cancel appointments) as shown in Fig. 10.

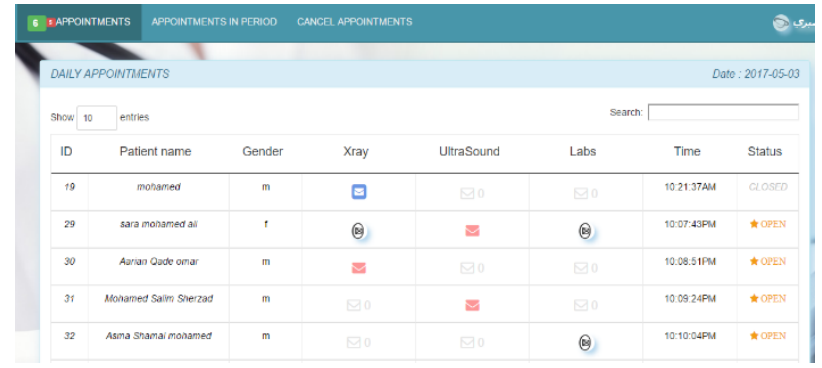

Figure 10 Physician module (daily appointments)
The diagnosis process of a specific patient starts with selecting the patient record directly or by searching the ID of the patient in the search field as shown in Fig. 11.

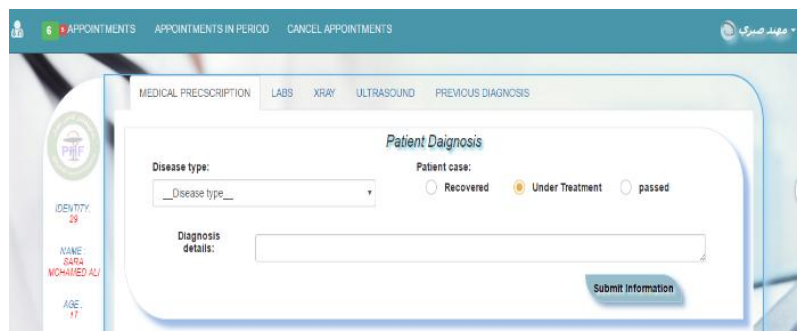

Figure 11 Physician module (medical prescription)

The doctor can exchange messages (required tests and results) with Lab, Ultrasound, Pharmacy and X-Ray Modules.

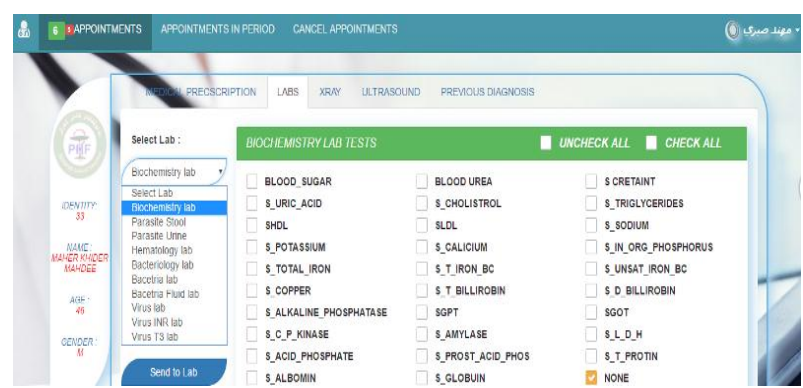

Figure 12 Physician module (test requesting from Lab)

The Labs that supported by the system are: Biochemistry lab, Parasite Stool and Urine lab, Hematology lab, Bacteriology lab, Bacteria lab, Bacteria Fluid lab, and Virus lab as shown in Fig. 13.

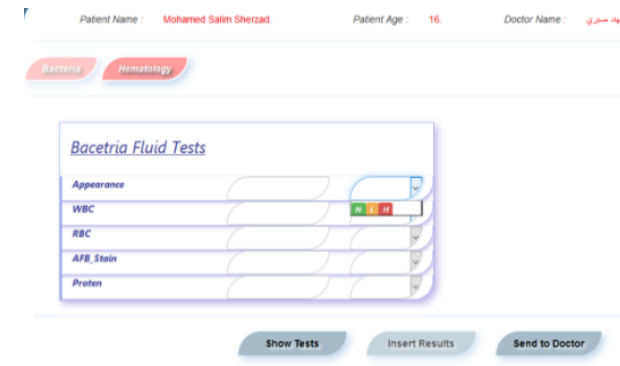

Figure 13 Lab module (Inserting tests results)

All available Labs tests can be added, edited and deleted dynamically through the Edit Tests page as shown in Fig. 14.

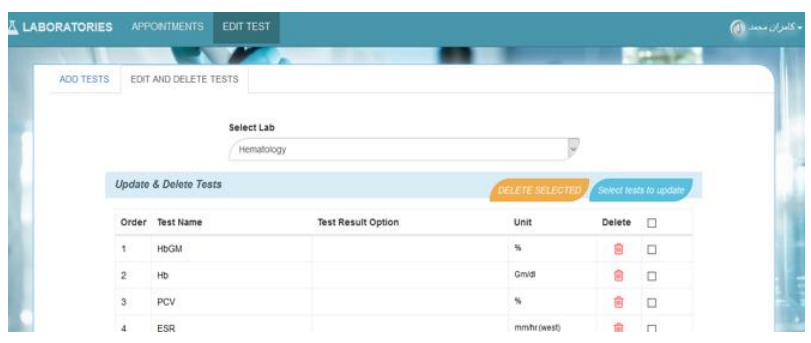

Figure 14 Lab module (Edit tests)

The reception and Information Desk module in Ehealthcare system has more roles than the traditional healthcare. He registers patients, reserve appointment for 
those patients willing to see specialist-physicians also print ID Card for patients as shown in Figures. $(15,16,17)$.

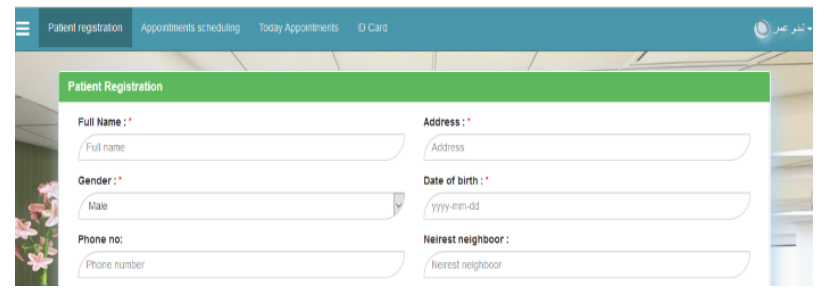

Figure 15 Reception Module (Patient Registration form)

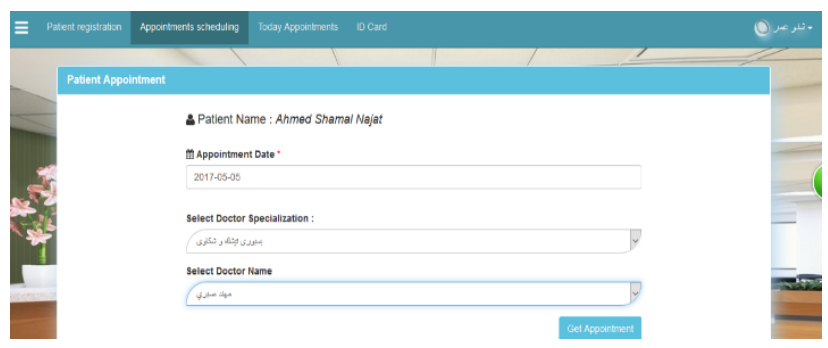

Figure 16 Reception Module (appointment scheduling)

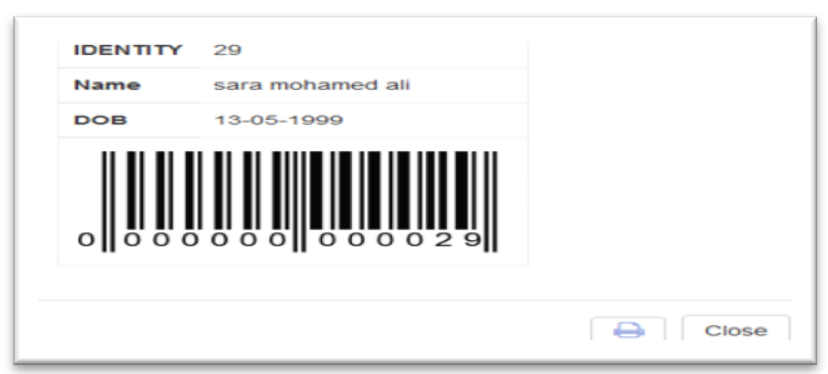

Figure 17 Reception Module (ID Card printing)

\subsection{Evaluation of the Proposed system}

The Evaluation procedure is very important to assess the implemented system. The questionnaire form is one of the depended styles to evaluate such systems. One of these efficient tools is the SUS that provides a quick and reliable way for measuring the usability. The SUS scores are in a 100.00 scale, which refers to the higher level of effectiveness, efficiency, and satisfaction in the use of the system. The SUS is composed of ten statements as shown in appendix (E), each statement has a five-point scale that ranges from Strongly Disagree to Strongly Agree. There are five positive statements and five negative statements, which alternate. These questions prepare average user satisfaction or dissatisfaction on a five-point scale. The odd-questions are positively worded and the even-questions are negatively worded [10]. The proposed system has been implemented practically in SGH. The testing period was about (44 days) from $(01 / 04 / 2017)$ to $(14 / 05 / 2017)$. The test period included training for (37) of hospital's staff (system's users). This helped to prepare special staff for the testing, the same users participated with the testing and evaluation processes. After finalizing the SUS questionnaire, the acquired SUS scores of the proposed system user's samples are processed as follow: For odd items: one subtracted from the user response. For even- numbered items: the user responses subtracted from 5 . The converted responses add up for each user and multiplied that total by 2.5 . This converts the range of possible values from 0 to 100 instead of from 0 to 40 .

Table 1: SUS scores by WBEHS participants

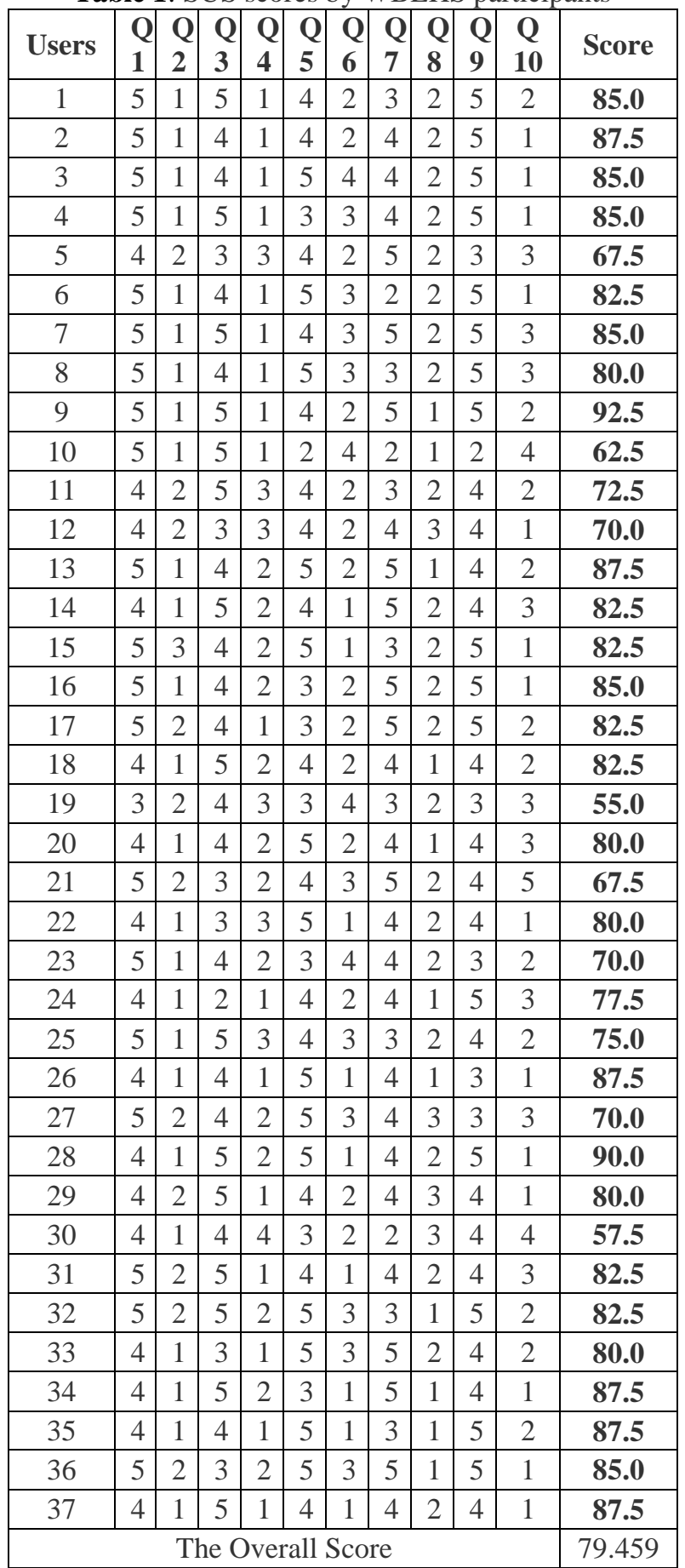

Table 1 shows that the slightest SUS score is (55.0) and the maximum score is (92.5). However, according to the mean of SUS scores, it can be determined that the provided system is generally seeming to be adequate depending on the SUS overall score which is (79.459). Fig. 18 characterizes the main survey results of (37) users participated in the WBEHS testing and evaluation. This graph produces more understanding about the 
system usability test and evaluation, which represent the user's opinions on usability issues of the system. It is clear from the plot that high scores have been presented at the positive questions while the negative ones produced lower values.

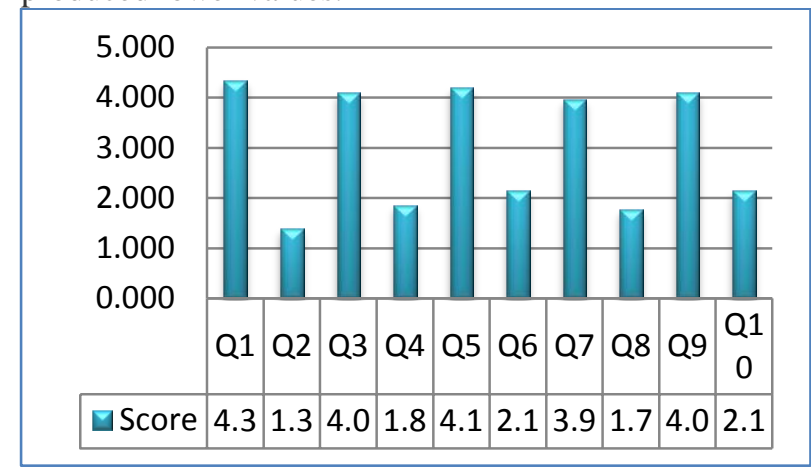

Figure 18 Mean Survey Results

Depending on the previous results obtained from the evaluation process, important facts concluded: The positive odd questions scores are ranging from (3.9) to (4.3) while the negative even questions score are ranging from (1.3) to (2.1) and this considered as a good result.

\subsection{Comparison the WBEHS with Previous Works}

The comparison can be done from tow views: Firstly, the software: the proposed system has been built with the latest tools that can't be found in the previous works. For example, (Laravel Framework, Bootstrap, Google reCaptcha) all these tools didn't used in the previous works. As well as more new features and flexibility. Secondly, the implementation and Evaluation: The proposed system has been implemented in SGH and evaluated by SUS, while the previous works tested and evaluated in the lab without real implementation.

\subsection{Problems Faced this work}

The barriers that faced this work can be listed as:

1) Economic problems: The economic crises have had a negative impact on all life facilities, and this led to delay in the implementation of the project because of the lack of the appropriate budget to purchase equipment and supplies for the project.

2) The people: Engaging doctors and other healthcare professionals in the new technologies are essential. Unfortunately, not everyone is on board with the idea of implementing and using e-health system. Some older doctors who do not have enough experience in using modern technology and computers prefer the traditional paper based method.

3) Coordination: There is no doubt that the program or system must be in line with the existing reality, with another intention that it should be applicable. This faces a big problem. While The number of patients diagnosed by the doctor exceeds 120 patients per day. And this number is unacceptable. So, it is the biggest problems that exhaust the staff, especially doctors. Therefore, this problem requires a radical solution by the Ministry of Health or other authorities.

\section{CONCLUSION}

An efficient WBEHS has been proposed, designed and implemented really in SGH. The proposed system improved to be the best alternative of the paper based system confirms the potential of this technology to aid patient care, increased administration efficiency, as well as better quality, safety and coordination of care. It correspondingly provides the reduction of important factors such as: consume-time, effort, cost (more economic). Profession statistics can be provided very simply and within little time for (daily, monthly and yearly) periods. These statistics are great steps toward Egovernment. The proposed system has been tested really for (44) days at SGH, (37) trainers participated with the testing who are (hospital staff and patients). The SUS questioner has been used to evaluate the proposed system. The overall evaluation score of the questionnaire was (79. 459\%) which can be considered as a good result.

\section{REFERENCE}

[1] Nations, U. (2014) UNITED NATIONS EGOVERNMENT SURVEY 2014, UNITED NATIONS.

[2] Claudio Di Carlo, E. S. (2012) "e-health in Italy: current state and future prospects of statistical information", Ministry of Economic Development Department of Communications, pp. 1-22.

[3] "eHealth Strategy for Ireland | Department of Health", Health.gov.ie, 2017. [Online]. Available: http://health.gov.ie/blog/publications/ehealthstrategy-for-ireland/. [Accessed: 06- Jun- 2017].

[4] A. Sunyaev, Health-Care Telematics in Germany, 1st ed. 65189 Weisbaden: Westdeutscher Verlag GmbH, 2011, pp. 40-45.

[5] ean-Claude Healy, "Implementing e-Health in Developing Countries Guidance and Principles", International Telecommunication Union (ITU), Geneva, 2008.

[6] O. B.O and O. M.O, "A framework for a multi-tier Internet Service architecture for doctors" directory", International Journal of Computers \& Technology, 2013, pp. 184-191.

[7] G. Mustafa, K. Faraj and S. Zeebaree, "Hand Writing Code-PHP Or Wire shark Ready Application Over Tier Architecture with Windows Servers Operating Systems or Linux Server Operating Systems" ICSE International Journal of Computer Sciences and Engineering, vol. 4, no. 6, pp. 142-149, 2016.

[8] C. Granja, K. Dyb, S. Roald Bolle and G. Hartvigsen, "On the Development of a HospitalPatient Web-Based Communication Tool: A Case Study from Norway", IOS Press, 2015.

[9] R. Hameed, O. Mohamad, O. Hamid and N. Tapus, "Design of e-Healthcare Management System Based on Cloud and Service Oriented Architecture", in The 5th IEEE International Conference on E-Health and Bioengineering - 
$E H B$, Grigore T. Popa University of Medicine and Pharmacy, Iasi, Romania, 2015, pp. 19-21.

[10]A. Bangor, P. Kortum and J. Miller, "Determining What Individual SUS Scores Mean: Adding an Adjective Rating Scale", JUS journal of Usability Studies, 2009, pp. 114-123.

\section{Biography}

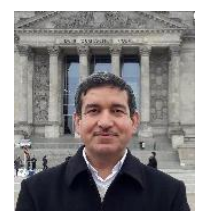

Dr. Subhi Rafeeq Mohammed Zeebaree is an Assistant Professor in Computer Engineering. He is the head of Computer and Communications Dept. at Nawroz University. He got his BSc, MSc and $\mathrm{PhD}$ Degrees from University of Technology-Baghdad-Iraq at 1990, 1995 and 2006 respectively. He is an Assistant Professor since 2012. He started teaching and supervising post-graduate courses (PhD and MSc) since 2007 and until now. Nineteen of his MSc students completed their studding and got MSc degree. Now there are number of PhD and MSc students under his supervising inside and outside of Iraq. He has joint $\mathrm{PhD}$ supervisions with UTM (Malaysia), Politecnico di Torino University (Italy), and EMU (Cyprus). He was head of IT Dept. at Akre Technical College (i.e. Technical College of Informatics-Akre) for three years at Duhok Polytechnic University (DPU). He was the Chairman of Scientific and Research Advices Committee of DPU for five years.

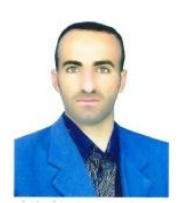

Mohamed Jasim Ahmed received the B.E. degree in electronic and control engineering from Northern Technical University, Kirkuk in (2003). He is currently working on his MSc thesis entitled (Design and Actual Implementation of eHospital System of Shorsh General Hospital at Kurdistan) in Information System Engineering at Erbil polytechnic university, Erbil, at 2015-2017. His research interests include design and real implementation of E-hospital system, programing language, questionnaire tools and analysis. He is a programmer and a web programing developer. 